\title{
PEMETAAN INDUSTRI PARIWISATA MALUKU SEBAGAI LANDASAN PERANCANGAN STRATEGI BRAND BARONDA MALUKU'
}

\author{
Rahman Muslim Moro Saimima, Alvanov Zpalanzani, \& Intan Rizky Mutiaz \\ Institut Teknologi Bandung \\ ramsie.saimima@gmail.com
}

How to cite (in APA Style): Saimima, R.M.M., Zpalanzani, A., \& Mutiaz, I. R. (2018). Pemetaan industri pariwisata Maluku sebagai landasan perancangan strategi brand 'Baronda Maluku'. Barista: Jurnal Kajian Bahasa dan Pariwisata, Vol. 5(2), Desember 2018, 145-157.

\begin{abstract}
Abstrak: Dalam menjalankan fungsi komunikasi pemasaran yang efektif, Dinas Pariwisata Maluku sebagai salah satu stakeholder pariwisata membutuhkan sebuah proses pengembangan keberlanjutan melalui perancangan strategi komunikasi pemasaran yang tepat guna untuk peningkatan jumlah wisatawan Nusantara pada khususnya. Metode penelitian yang digunakan adalah deskriptif kualitatif dengan penerapan analisis data melalui model SOSTAC + 3Ms planning system (Situation, Objective, Strategy, Tactics, Action, Control, Men, Minutes, and money) dengan penilaian secara objektif, empirik dan sistematik. Temuan penelitian menunjukkan bahwa: (1) industri pariwisata Maluku memiliki potensi wisata sejumlah 440 wisata bahari, 222 wisata budaya/sejarah, 39 wisata buatan, 6 atraksi acara berskala nasional dan internasional, 235 fasilitas akomodasi, 61 transportasi laut dan udara serta 1.739 fasilitas pendukung (2) strategi komunikasi pemasaran yang dijalankan menitik-beratkan pada media lini bawah (below the line) dengan cakupan pasar Nusantara yang rendah sehingga dibutuhkan pengembangan strategi media melalui komunikasi pemasaran terpadu (intergrated marketing communication).
\end{abstract}

Kata kunci: eksisting; grand strategy; komunikasi pemasaran

\section{MAPPING OF MALUKU TOURISM INDUSTRY AS A BASE OF BRAND 'BARDONDA MALUKU' DESIGN STRATEGY}

\begin{abstract}
In executing effective marketing communication function, Tourism Office of Maluku as one of tourism stakeholder needs a process of sustainable development through appropriate marketing communication strategy design to increase the number of national tourists in particular. The research method used is descriptive qualitative with the application of data analysis through SOSTAC model 3Ms planning system (Situation, Objective, Strategy, Tactics, Action, Control, Men, Minutes, and Money) with objective, empirical and systematic assessment. The research findings show that: (1) the tourism industry of Maluku has a tourism potential of 440 marine tourisms, 222 cultural/historical tours, 39 artificial tours, 6 national and international event attractions, 235 accommodation facilities, 61 sea and air transportations and 1,739 support facilities (2) marketing communications strategy undertaken emphasizes on below the line media with low coverage of the national market, therefore media strategy development through integrated marketing communication is needed.
\end{abstract}

Keywords: existing; grand strategy; marketing communication 


\section{PENDAHULUAN}

Kepariwisataan pengembangan pendekatan pemerataan $\begin{array}{cr}\text { dalam } & \text { proses } \\ \text { pembangunan } & \text { melalui } \\ \text { pertumbuhan } & \text { dan } \\ \text { ekonomi } & \text { untuk }\end{array}$ kesejahteraan rakyat yang berorientasi pada pengembangan wilayah, yang didalamnya memiliki beberapa aspek, seperti sumber daya manusia, pemasaran, destinasi, ilmu pengetahuan dan teknologi, keterkaitan lintas sektor, kerja sama antarnegara dan provinsi, pemberdayaan usaha kecil, serta tanggung jawab dalam pemanfaatan sumber kekayaan alam dan budaya secara berkelanjutan.

Provinsi Maluku, salah satu wilayah dibagian Timur Indonesia memiliki 12 gugusan pulau-pulau kecil dengan potensi wisata alam bahari, sosial budaya, sejarah dan kuliner yang beragam yang tersebar di Sembilan kabupaten dua kota, yang diantaranya :
Kabupaten Maluku Tengah, Kabupaten Seram Bagian Barat, Kabupaten Seram Bagian Timur, Kabupaten Maluku Tenggara, Kabupaten Aru, Kabupaten Maluku Tenggara Barat, Kabupaten Maluku Barat Daya, Kabupaten Buru Selatan, Kabupaten Buru, Kota Ambon dan Kota Tual.

Pengembangan kepariwisataan dilakukan melalui peningkatan daya tarik wisata, penetapan jalur wisata, kalender wisata, informasi dan promosi wisata merupakan salah satu langkah kongkrit dalam menjalankan strategi pemasaran yang sudah ditentukan melalui komunikasi tepat guna. Parameter keberhasilan kepariwisataan dapat terukur dari jumlah tingkat kunjungan wisatawan Mancanegara, Nusantara maupun Lokal yang berkunjung ke daerah Maluku. Berikut grafik jumlah kunjungan wisatawan pada tahun 2014-2016:

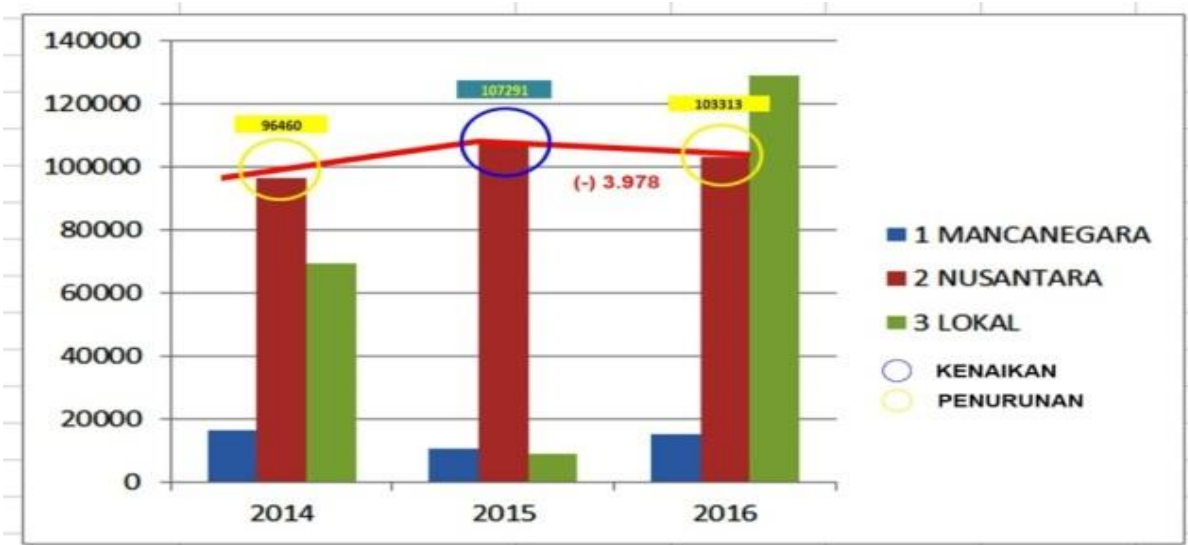

Grafik I.1 Jumlah Kunjungan Wisatawan

Mancanegara-Nusantara-Lokal (2014-2016)

Sumber : Dinas Pariwisata Provinsi Maluku.

Berdasarkan data grafik I.1 diatas, terlihat bahwa wisatawan yang telah berkunjung ke Provinsi Maluku pada tahun 2016 mengalami kenaikan pada wisatawan lokal (wislok) dengan total jumlah 129.068 wisatawan, adapun jumlah penurunan pada wisatawan Nusantara (wisnus) ditahun 2016 sebesar minus 3.978 dan penetrasi bertahap terjadi pada wisatawan Mancanegara (wisman) sejumlah 15.015 wisatawan. Melihat lampiran data tersebut, lonjakan yang terjadi pada wislok pada tahun 2016 disebabkan oleh adanya kegiatan berskala daerah dan nasional seperti ; Patai Konci Taong (Tutup Tahun Baru), Festival Teluk Ambon, Pesparawi Nasional dan Darwin Race yang berlangsung pada bulan September sampai dengan bulan Desember 2016, sedangkan jumlah 
wisnus dan wisman terjadi penurunan dan stagnansi di akhir tahun 2016.

Hasil analisis yang dikeluarkan oleh peneliti adalah (a) melihat peluang dari kondisi existing di kota ambon yang diantaranya; wisata taman laut, agrowisata, wisata kuliner dan wisata budaya seni untuk dipasarkan ke calon wisatawan Mancanegara dan Nusantara (b) identifikasi permasalahan mengenai strategi perencanaan pengembangan industri pariwisata yang sudah dilakukan oleh pemerintah kota Ambon berupa faktor pengembangan wisata alam, strategi alternative progresif, strategi diservikasi, market penetration dan product development. Penelitian sebelumnya memiliki cakupan area terbatas dengan hasil yang didapatkan menunjukkan bergeraknya kunjungan wisatawan kearah trend positif. Melalui penelitian kali ini, penulis mengembangkan cakupan area penelitian dengan skala area lebih besar dengan menitik-beratkan kepada wisatawan Nusantara dengan rumusan masalah; (a) mengetahui faktor internal dan eksternal yang mempengaruhi pariwisata Maluku dalam menjalankan strategi komunikasi pemasaran terdahulu dengan merumuskan perencanaan Grand Strategy komunikasi pemasaran wisata melalui sistem analisis model SOSTAC+3M yang dipaparkan oleh "P.R Smith (1999: hlm 110)", (b) Menyusun perancangan strategi komunikasi pemasaran objektif melalui 'Baronda Maluku' sebagai brand regular dalam mengakomodir permintaan primer pasar Nusantara (primary demand).

\section{METODE}

Penelitian ini bersifat deskriptif kualitatif. Bersifat deskriptif yaitu suatu metode penelitian yang berusaha mendeskripsikan atau menggambarkan fenomena atau hubungan antara fenomena yang diteliti dengan sistematis, faktual dan akurat. "Natsir (1998)".

Penelitian ini menggambarkan tentang kondisi eksisting yang dimiliki oleh Maluku, strategi komunikasi pemasaran yang telah dilakukan dan mengumpulkan tanggapan kebutuhan responden wisatawan Nusantara terhadap obyek wisata Maluku berdasarkan kuesioner serta wawancara yang dilakukan. Pelaksanaan penelitian dilakukan pada bulan Desember 2017 dan bulan April 2018 dengan lokasi di Bandara Internasional Pattimura, destinasi wisata; pantai Hunimua, pantai Natsepa-Maluku Tengah, Gong Perdamaian Dunia-Ambon dan Pantai Ora-Maluku Tengah yang berada dalam wilayah administrasi Provinsi Maluku.

Populasi responden sebanyak 54 wisatawan Nusantara selama dua bulan terakhir yang telah berdiam minimal selama 1-6 hari di wilayah Maluku. Sampel penelitian untuk wisatawan Nusantara ditetapkan secara accidental sampling, yaitu teknik penentuan sampel berdasarkan kebetulan, siapa saja yang bertemu dengan peneliti dan cocok sebagai sumber data, maka dapat digunakan sebagai sampel. Setiap wisatawan Nusntara yang dijumpai di lima lokasi penelitian langsung diambil secara acak dan diberikan kuesioner melalui form kuesioner digital (google form) serta diwawancara secara langsung.

\section{HASIL DAN PEMBAHASAN}

\section{A. Gambaran Umum Kondisi Wilayah Maluku}

Provinsi Maluku adalah salah satu dari 34 provinsi bagian Timur yang dimiliki oleh Negara Kesatuan Republik Indonesia (NKRI). Secara astronomis, Provinsi Maluku terletak antara 2030- $9^{0}$ Lintang Selatan dan 1240' - 1360' Bujur Timur. Berdasarkan data Sekretaris Daerah Provinsi Maluku yang tertuang dalam RPJMD Provinsi Maluku Tahun 2014 - 2019, Provinsi Maluku merupakan wilayah kepulauan dengan jumlah pulau sebanyak 1.340 pulau dengan panjang garis pantai sebesar $11.000 \mathrm{~km}$. 
Tabel I.1 Gambar Batasan Wilayah Maluku kabupaten/kota

\begin{tabular}{|c|c|c|c|}
\hline No. & Kabupaten/Kota & Ibukota & $\begin{array}{l}\text { Luas Wilayah } \\
\left(\mathrm{Km}^{2}\right)\end{array}$ \\
\hline 1. & Kabupaten Buru & Namlea & $7.595,58$ \\
\hline 2. & Kabupaten Buru Selatan & Namrole & $5.060,00$ \\
\hline 3. & Kabupaten|Kepulauan Aru & Dobo & $6.426,77$ \\
\hline 4. & Kabupaten Maluku Barat Daya & Tiakur & $72.423,61$ \\
\hline 5. & Kabupaten Maluku Tengah & Masohi & $11.595,57$ \\
\hline 6. & Kabupaten Maluku Tenggara & Langgur & $4.212,34$ \\
\hline 7. & Kabupaten Maluku Tenggara Barat & Saumlaki & $52.995,19$ \\
\hline 8. & Kabupaten Seram Bagian Barat & Piru & $6.948,40$ \\
\hline 9. & Kabupaten Seram Bagian Timur & Bula & $5.779,12$ \\
\hline 10. & Kota Ambon & Ambon & $35.944,62$ \\
\hline 11. & Kota Tual & Tual & 254,39 \\
\hline
\end{tabular}

Daya tarik obyek wisata yang begitu banyak dan tersebar diseluruh penjuru kepulauan Maluku perlu dipetakan secara deskripsi maupun secara spasial sehingga distribusinya menjadi terlihat dan untuk selanjutnya dapat menjadi bahan acuan bagi pemangku kepentingan maupun bagi wisatawan Nusantara sebagai pengguna informasi tersebut. Secara ringkas jumlah daya tarik wisata menurut kabupaten/kota, yaitu :

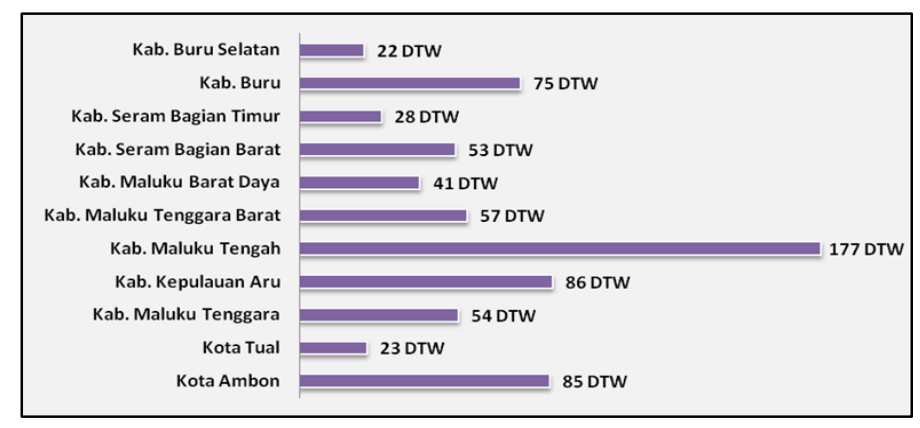

Grafik I.2 Jumlah Daya Tarik Wisata

Menurut Kabupaten/Kota dan Gugus Pulau

Sumber: Dinas Pariwisata Provinsi Maluku 2017

Jika dikelompokkan berdasarkan jenis daya tarik wisata, nampak daya tarik wisata alam mendominasi potensi kepariwisataan di Provinsi Maluku, yaitu sebesar $64 \%$ atau sejumlah 440 objek, diikuti daya tarik wisata budaya/sejarah $32 \%$ atau 222 objek dan sisanya daya tarik wisata buatan sebesar $5 \%$ atau 39 objek.

\section{B. Pemetaan Industri Pariwi-sata Provinsi Maluku}

Provinsi Maluku dalam pengembangan kepariwisataan kedepan tidak luput dari pengembangan beberapa sektor pendukung untuk memajukan kepariwisataan nya. Adapun sektor-sektor yang mendukung se-bagai berikut ; 
Tabel I.3 Jumlah Industri Pariwisa Maluku tahun 2017

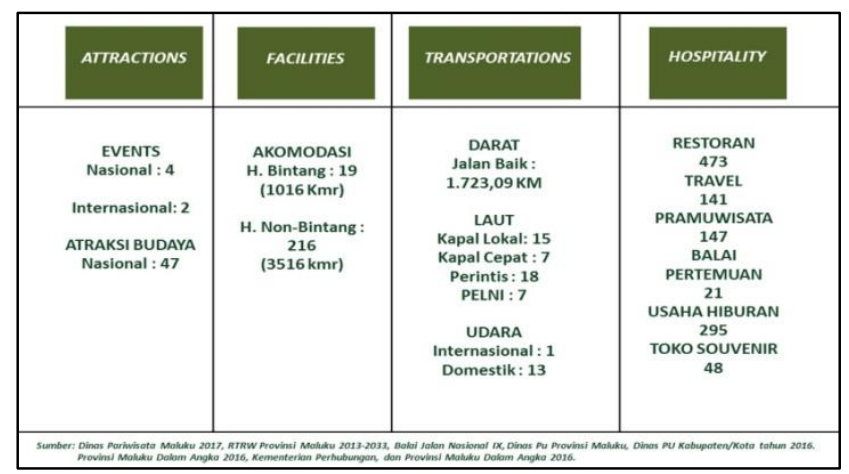

Sumber: Dinas Pariwisata Provinsi Maluku 2017

\section{Daya Tarik (Attraction)}

Dinas Pariwisata Provinsi Maluku pada tahun 2017-2018 ini memiliki program Event Attractions sejumlah enam dengan skala Nasional dan Internasional seperti; (1) Festival Jalur Rempah di tiga pulau (Banda, Saparua dan Ambon), (2) Festival Teluk Ambon (Ambon), (3) Tour de Molvcass (jalur Seram Bagian Timur, Seram Bagian Barat, Maluku Tengah dan Kota Ambon), (4) Pesta Rakyat Banda (Maluku Tengah) dan (5) Patai Konci Taong (Acara Tutup Tahun-Ambon) dan (6) atraksi budaya sejumlah 47 dengan skala Nasional.

\section{Fasilitas (Facilities)}

Peran usaha pariwisata dapat pula membantu meningkatkan perkembangan pariwisata Maluku tidak terlepas dari dukungan usaha akomodasi dan perjalanan wisata. Berikut rincian daftar usaha pariwisata yang ada di Provinsi Maluku; (1) Hotel non-bintang sejumlah 216 hotel dengan 3516 kamar, dan (2) Hotel berbintang sejumlah 19 hotel dengan 1016 kamar.

\section{Transportasi (Transportations)}

a) Transportasi Darat; Pada tahun 2016, berdasarkan data dari Balai Jalan Nasional IX, Dinas Pekerjaan Umum Provinsi Maluku dan Dinas Pekerjaan Umum Kabupaten/Kota, panjang Jalan Nasional mencapai $1.771,67 \mathrm{~km}$ dan panjang jalan Provinsi mencapai 1.080,3 $\mathrm{km}$. b) Transportasi Laut; pembagian transportasi laut yang dimiliki oleh Provinsi Maluku sebagai berikut: (1) 15 Kapal Lokal (2) 7 Kapal Cepat (3) 18 Kapal Perintis (4) 7 Kapal PELNI.

c) Transportasi Udara; sesuai dengan UU No. 1 tentang Penerbangan dan PM. 69 tahun 2013 tentang Tatanan Kebandara Udaraan Nasional, maka berdasarkan Hirarkinya Bandara Udara terdiri atas; (1) Bandar Udara Pengumpul (Hub), (2) Bandar Udara Pengumpan (Spoke) dengan pembagian sebagai berikut; (1) 1 Bandara Internasional, dan (2) 13 Bandara Domestik.

\section{Keramah-tamahan (Hospitality)}

Pengembangan Sumber Daya Manusia (SDM) di bidang Pariwisata Maluku diarahkan pada penguasaan kompetensi di bidangnya. Salah satu bentuk sumbangsih nyata sektor pariwisata yang diterapkan oleh dinas Pariwisata Maluku adalah aspek pemberdayaan masyarakat di sekitar objek wisata, dimana masyarakat dilibatkan langsung dalam berbagai metode kegiatan praktik dan teoritis yang kedepan dijadikan bekal bagi pengembangan usaha, khususnya Usaha Mikro Kecil Dan Menengah (UMKM), yang bermuara pada peningkatan kesejahteraan masyarakat. Adapun usaha-usaha tersebut diantaranya; (1) 473 restoran (2) 141 travel (3) 147 pramuwisata (4) 21 balai 
pertemuan (5) 295 usaha hiburan (6) 48 toko souvenir.

Dengan melihat data jumlah industri kepariwisataan yang dimiliki oleh Maluku saat ini, dapat terlihat bahwa Maluku siap bersaing untuk kancah Nasional dibidang kepariwisataan baik dari lini; atraksi, fasilitas, transportasi serta fasilitas penunjang lainnya.

\section{Strategi Promosi Pengembangan Pemasaran Dinas Pariwisata}

Dalam dunia kepariwisataan, faktor internal pemasaran khususnya dalam menjalankan strategi komunikasi yang ditentukan oleh bidang pengembangan pemasaran pariwisata sangatlah penting, dikarenakan strategi yang telah dirumuskan merupakan ujung tombak dari keseluruhan instrument pariwisata dalam meningkatkan tingkat kunjungan wisatawan khususnya wisatawan Nusantara. Hasil analisis dengan model SOSTAC $+3 \mathrm{M}$ yang dilakukan oleh penulis adalah sebagai berikut:

\section{Situation (situasi)}

Terdapat hasil statistik kunjungan wisatawan Nusantara yang didapatkan melalui beberapa titik pintu masuk, yang diantaranya melalui Pelabuhan Yos Sudarso kota Ambon, Bandara Internasional Pattimura, hotel /penginapan serta Polda/Polsek. Adapun wilayah survey dibagi menjadi tiga wilayah, diantaranya; (a) statitistik kepariwisataan di 9 Kabupaten 2 kota (b) Analisa pasar Nusantara dilakukan di Kota Ambon. Mengenai hasil perhitungan kunjungan wisatawan yang dibagi menjadi tiga di tahun 2014 sampai dengan tahun 2016, dan dapat terlihat dari grafik data kunjungan wisatawan Nusantara dan Asal Kota, yaitu;

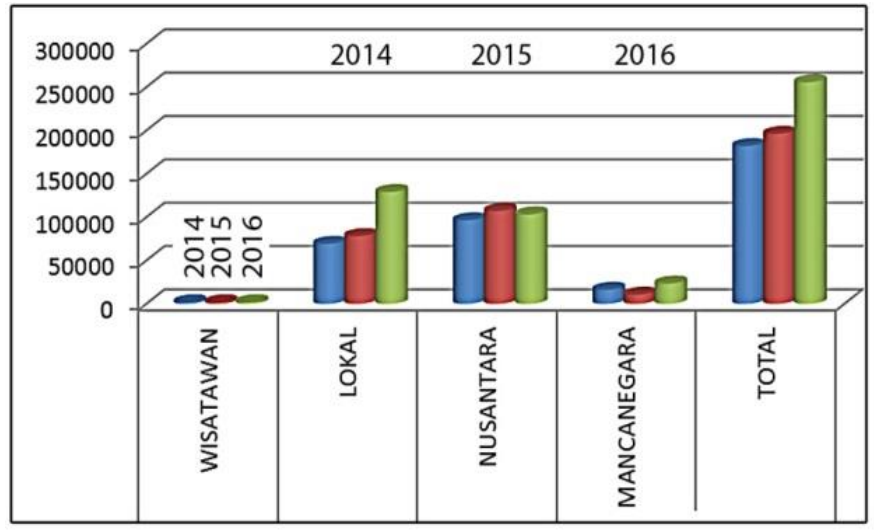

Grafik I.3 Grafik Kunjungan Wisatawan Mancanegara VS Nusantara VS Lokal Sumber: Bidang Pemasaran, Dinas Pariwisata Provinsi Maluku 2017

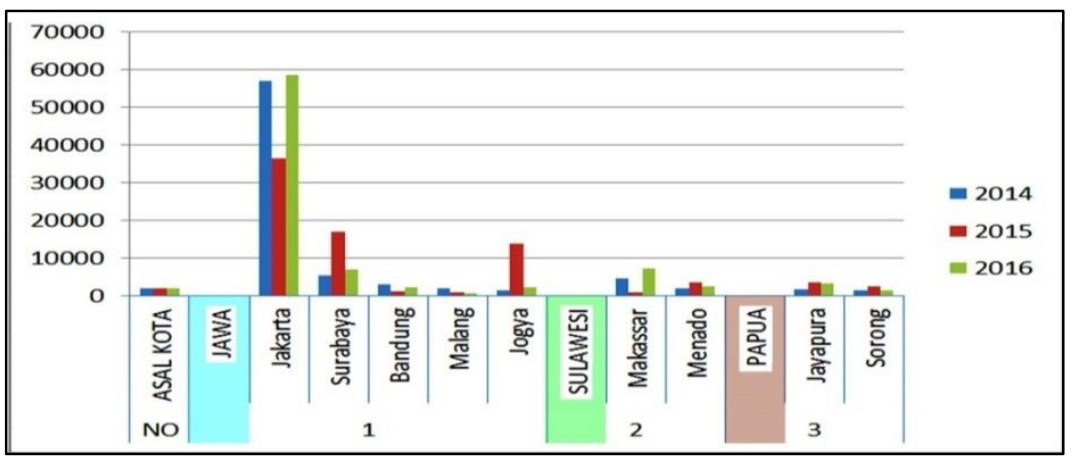

Grafik I.4 Grafik Kunjungan Wisatawan Asal Kota

Sumber: Data Olahan Peneliti 2018 
Melihat grafik kunjungan wisatawan Nusantara dan asal kota pada tahun 2014-2016 diatas, dapat disimpulkan:

1. Pada tahun 2014 jumlah kunjungan wisatawan Nusantara berjumlah 96.459 wisatawan yang didominasi kunjung tertinggi dari asal pulau; Jawa (dominasi kota Jakarta, Surabaya, Jogya dan Bandung) dengan sub-total 70.276 wisatawan, Sulawesi (dominasi kota Makasar dan Menado) dengan sub-total 8.370 wisatawan disusul asal daerah Papua (dominasi kota Jayapura dan Sorong) dengan Sub-total 5.686 wisatawan.

2. Puncak Arus kedatangan wisatawan Nusantara tahun 2014 bisa terlihat pada bulan; Maret, Juni dan Agustus dengan nilai rata-rata berkisar 9.500-an wisatawan. Hal ini dipicu dengan adanya agenda acara Nasional yang diselenggarakan di kota Ambon yaitu (MTQ Nasional, HUT Kota Ambon dan Festival Teluk Ambon) dan pemilihan media komunikasi melalui TV (Kompas TV, SCTV, INDOSIAR, TRANS7) dan Radio RRI, Koran Nasional (Kompas) dan Cetakan.

3. Pada tahun 2015 jumlah kunjungan wisatawan Nusantara meningkat dengan jumlah 107.291 wisatawan yang didominasi kunjung tertinggi dari asal pulau; Jawa (dominasi kota Jakarta, Surabaya, dan Jogya) dengan sub-total 78.137 wisatawan, Sulawesi (dominasi kota Makasar dan Menado) dengan sub-total 8.370 wisatawan disusul asal daerah Papua (dominasi kota Jayapura dan Sorong) dengan Sub-total 8.222 wisatawan. Jumlah total kunjungan wisatawan Nusantara diatas masih bersifat sementara mengingat data yang terlampir hanya terisi sampai dibulan ke tiga (Januari-maret) dikarenakan faktor alam (force major) sehingga sisa data di bulan April - Desember tidak dapat dilampirkan. Akan tetapi, jika merujuk pada data BPS Maluku Dalam Angka tahun 2017, kunjungan wisatawan Nusantara masih mengalami peningkatan sejumlah total 110.699 wisatawan.

4. Jika mengacu pada data wisnus, puncak Arus kedatangan wisatawan Nusantara pada tahun 2015 bisa terlihat pada bulan; Maret dengan nilai rata-rata berkisar 34 ribu wisatawan yang berkunjung ke Maluku. Hal ini dipicu dengan adanya agenda acara Nasional yang diselenggarakan di kota Ambon yaitu Pesparawi Nasional dan pemilihan media komunikasi melalui TV (Kompas TV, SCTV, INDOSIAR, TRANS7) dan Radio RRI, Koran Nasional (Kompas).

5. Sedangkan pada tahun 2016 jumlah kunjungan wisatawan Nusantara terjadi penurunan berjumlah 103.947 wisatawan dengan selisih wisatawan sebelumnya sebesar 3.344 wisatawan. Penurunan wisatawan kali ini didominasi dari asal daerah; Jawa (dominasi kota Jakarta, Surabaya, Jogya dan Bandung) dengan sub-total 71.278 wisatawan terjadi selisih penurunan sebesar 6.859 wisatawan.

6. Penurunan kedatangan wisatawan Nusantara ditahun 2016 bisa terlihat pada bulan; Maret, Juli dan September dengan nilai rata-rata berkisar 3.000-an wisatawan. Hal ini dipicu dengan kurangnya penyebaran media promosi secara merata kepada calon wisatawan dari pulau Jawa khususnya kota Surabaya, Bandung, Malang dan Jogya.

Dari data survey awal tentang minat kunjungan wisnus, penulis melakukan pengembangan survey dan kajian lanjutan. Dalam konteks pemasaran pariwisata, pemasaran lebih mudah dijelaskan dengan kata kunci "memahami keinginan dan kebutuhan wisatawan merupakan titik awal kegiatan pemasaran wisata". Hasil data kuesioner yang dikumpulkan dari beberapa 
destinasi wisata di kota Ambon dan Maluku Tengah adalah Jumlah wisatawan Nusantara yang teramati secara random adalah sejumlah 54 wisatawan dari asal kota Jakarta (43\%), Jawa Barat (26\%), Jawa Timur (9\%), Jawa Tengah (7\%), Sumatera Utara (4\%), Sumatera Barat (4\%), Bali (2\%), Kalimantan (2\%), Sulawesi (2\%) dan Papua (2\%). Dari keseluruhan responden tersebut didominasi oleh responden berjenis kelamin Wanita yaitu sebesar 52\%, sementara jumlah responden laki-laki hanya sebesar 48\%, dengan kelompok usia dibagi menjadi tiga bagian yaitu; usia 20-30 tahun sebesar 50\%, usia 31-40 tahun sebesar 33\% dan usia 41-60 sebesar $17 \%$. Jenis pekerjaan didominasi oleh pekerja swasta sebesar 52\% yang melakukan perjalanan khusus berwisata ke Maluku. Hal ini didukung oleh pilihan motivasi perjalanan yaitu liburan (rekreasi) sebesar 70\%, bisnis 2\%, tugas dinas $28 \%$ dengan prioritas aktivitas menikmati keindahan pantai (wisata pantai) sebesar $39 \%$ dan melakukan diving/snorkeling (wisata laut) sebesar $35 \%$.

Melihat hasil data kuesioner dari frekuensi wisatawan Nusantara dalam penggunaan perangkat pencarian informasi berwisata ke Maluku dapat terlihat data survey wisnus dari $\mathrm{N}=54$ adalah dengan menggunakan perangkat; Handphone $61 \%$, komputer $12 \%$, televisi $11 \%$, dan media cetak 6\%. Fenomena diatas dapat disimpulkan bahwa alasan tertinggi dalam kebutuhan wisatawan Nusantara saat ini adalah;

a) Dibutuhkan sebuah konvergensi media dari media konvensional menjadi New Media berupa perangkat/system software berbasis web atau aplikasi (App) yang dapat mempermudah wisatawan Nusantara dalam mempelajari produk wisata Maluku secara lengkap, baik ketersediaan destinasi wisata, penunjuk arah, transportasi, akomodasi serta elemen wisata pendukung lainnya. b) Dapat dipergunakan dengan mudah kapanpun dan dimanapun disaat dibutuhkan yang memiliki unsur; efektifitas, efisiensi, informatif dan atraktif.

\section{Objective (Tujuan)}

Dalam objektifitas, menurut (Morissan, 2010: hlm 42), menekankan bahwa dalam membahas mengenai objective/tujuan perusahaan perlu memahami adanya perbedaan antara tujuan pemasaran (marketing objectives) dan tujuan komunikasi (communication objectives). Dalam konteks penelitian ini, tujuan pengembangan komunikasi pemasaran Provinsi Maluku lebih diutamakan kedepan, agar wisatawan Nusantara dapat langsung menerima dan merespon informasi yang diberikan, sehingga dapat menghasilkan aksi secara cepat dan terukur. Adapun pendekatan strategi komunikasi yang akan dituju harus didasari atas;

\section{a) Brand Awarness (Kesadaran Merek) \\ Penulis memasukan beberapa kata} kunci ke system google analytic dalam periode 2017-2018. Dari kata kunci: (a) Maluku/Molucass Beach (b) Maluku/Molucass Tourism (c) Maluku/Molucass Eco Tourism dan (d) Baronda Maluku, dapat terlihat interest over timenya, 'Baronda Maluku' dalam satu tahun lebih mendominasi sejumlah 393 pencarian dibandingkan dengan kata kunci lainnya sejumlah 0 (nol) pencaharian. Untuk interest by region Maluku terlihat Negara Indonesia lebih mendominasi dibandingkan negara lainnya. dapat disimpulkan bahwa nama yang akan dibutuhkan oleh pasar Nusantara untuk merek/brand promosi Pariwisata Maluku adalah 'Baronda Maluku' dengan tagline 'Sensasi Seribu Pulau'.

\section{b) Strategi Intergrasi ke depan :}

Menempatkan brand 'Baronda Maluku' kedalam sebuah perancangan media promosi tepat guna, diantaranya; 
a) Aplikasi Media Online (Primary demand) :

Web E-Tourism Guide (App) melalui perangkat smartphone/Android dengan pemilihan konten sesuai dengan kebutuhan wisatawan Nusantara melalui hasil data kuesioner dilapangan, seperti: (a) Konten Destinasi Wisata (b) Konten Maps (c) Konten Transportasi dan Akomodasi (d) Konten Paket Wisata (e) Konten Promo (f) Konten Video/360 dan (g) Konten Sosial Media sebagai permintaan primer pasar Nusantara.

b) Media Ruang dan Video (Secondary demand) : Baliho, Billboard, merchandiser, teaser/video, poster, pop Ads, jingle ads, infographic, events booth sebagai media promosi non-regular yang di konvergensikan melalui sosial media dan booth digital.

\section{Strategy (Perencanaan)}

Perencanaan strategi komunikasi pemasaran brand 'Baronda Maluku' sebaiknya menggunakan unsur-unsur bauran promosi (Promotion Mix) karena pemasaran menggunakan berbagai jenis promosi secara terintegrasi dalam suatu promosi produk/korporat. (Smith (1999: hlm11).

a) Interactive Marketing; Menetapkan media promosi Lini Atas (ATL) yaitu E-Tourism Guide 'Baronda Maluku' sebagai media promosi regular untuk wisatawan Nusantara.

b) Advertising; Kampanye iklan dengan media komunikasi visual seperti; (1) Teaser/Video 'Baronda Maluku' App (2) Billboard (3) Jingle Ads (4) Promo Ads (5) Events (6) Exhibitions dan (7) infographic yang berisikan tentang kebutuhan produk wisata yang diminati audiens (user aplications positioning) dan disertakan manfaat produk (benefit positioning) bagi pasar.

c) Sales Promotion; melakukan kegiatan acara Travel Mart Indonesia yang disesuaikan dengan data survey di beberapa kota besar seperti Jakarta, Papua, Makasar, Surabaya, Bandung, Jogya dan Bali.

d) Public Relation; (1) Membuat acara Fam Trip Media Nasional dengan melakukan kegiatan outbond activity di beberapa destinasi wisata unggulan di Provinsi Maluku dengan hasil publikasi destinasi dalam bentuk bentuk komunikasi non-personal yaitu berita (news story form), dan (2) Membuat Talk Show di stasiun radio yang mengangkat tentang informasi brand 'Baronda Maluku'.

e) Personal Selling; Menempatkan booth digital brand 'Baronda Maluku' di bandara Nasional dan Internasional dibeberapa kota besar Indonesia guna memudahkan calon wisatawan Nusantara untuk mendapatkan informasi berwisata ke Maluku secara cepat, tepat dan efisien.

\section{Tactic (Taktik);}

Taktik yang diusulkan untuk dilakukan oleh Dinas Pariwisata Maluku bersama stakeholder pariwisata 11 Kabupaten/Kota, sebagai berikut:

(a) Taktik Pertama; mengadakan Konsolidasi Daerah/Nasional yang mengundang perwakilan-perwakilan asosiasi lembaga pariwisata seperti Perhimpunan Hotel dan Restauran Indonesia (PHRI), Asosiasi Perusahaan Perjalanan Indonesia (ASITA), perusahaan maskapai penerbangan seperti; PT. Garuda Indonesia, PT. Lion Mentari Airlines, PT. Sriwijaya Air, PT. Citylink Airlines dan Kementerian Pariwisata sebagai National Tourist Office (NTOs) untuk bekerjasama dalam mempromosikan program strategi brand 'Baronda Maluku' yang sudah dirancang oleh Dinas Pariwisata Maluku sebelumnya.

(b) Taktik Kedua; merumuskan time scheduling dengan data 'Jadwal Piknik Liburan Tahun 2018' yang dikeluarkan oleh Kementerian 
Pariwisata untuk dapat membuat garis acuan waktu/jadwal promosi brand 'Baronda Maluku' sehingga dapat terukur, terarah dan tepat sasaran.

(c) Taktik Ketiga; mengadakan Fam Trip Media Nasional yang mengundang perwakilan-perwakilan media untuk melakukan outbond activity di Maluku dengan output mengulas tentang destinasi-destinasi wisata unggulan Maluku melalui tulisan sekaligus me-launching program aplikasi E-Tourism Guide 'Baronda Maluku'.

(d) Taktik Keempat; meningkatkan promosi dan publikasi melalui jaringan internet (sosial media), penempatan booth digital di bandara-bandara internasional, branding logo 'Baronda Maluku' dibeberapa media online, serta event-event Nasional.

(e) Taktik Kelima; melakukan Marketing Research Colaborations yaitu dengan melakukan survey dan kajian pasar wisata Nusantara mengenai impact paska menjalankan strategi komunikasi pemasaran yang terintergrasi kedepan dengan evaluasi ketepatan strategi dan mengukur tiga lapis efektivitas program yaitu; output yang mengukur sebatas pemunculan atau pemuatan pesan melalui media (message transmission); outgrowth yang mengukur sejauh mana pesan bisa dipahami publik (message reception); sementara outcome mengukur pengaruh pesan terhadap perubahan opini, persepsi, sikap dan perilaku khalayak (message effect) pada sebuah media promosi visual.

\section{Action (Aksi/Implementasi);}

Implementasi yang telah dilakukan oleh Dinas Pariwisata Maluku dalam menjalankan program promosi pariwisata masih dilakukan sebatas pemilihan media konvensional, penempatan dan jumlah media dengan area terbatas. Disini terlihat bahwa butuh adanya pengembangan strategi aksi melalui penyusunan jadwal penempatan media (media outline) selama satu tahun sehingga pemasar dapat mengetahui secara jelas untuk menjalankan program branding 'Baronda Maluku' kedepannya secara tepat.

\section{Men (Sumber Daya Manusia);}

Melihat Sumber Daya Manusia (SDM) yang dimiliki oleh Dinas Pariwisata Maluku saat ini, jumlah karyawan yang terdapat di kedinasan berjumlah 77 orang (ASN) dan 60 orang (karyawan kontrak). Survey data mencatat bahwa sumber daya manusia di bidang Pemasaran belum memiliki SDM yang memiliki kompetensi berbasis IPTEK, sehingga butuh perhatian khusus kepada Dinas Pariwisata kedepannya perlu adanya pengadaan SDM yang berkualitas mengingat era digital merupakan ujung tombak dalam mempromosikan sebuah produk.

\section{Money (Dana);}

Dana untuk program komunikasi pemasaran sesuai dengan Rencana Anggaran Pengembangan Pariwisata tahun anggaran 2017 sebesar Rp. 16.265.700.000.000,- dan adanya kenaikan di tahun 2018 dengan total nilai Rp. 18.950.000.000,-. Dengan melihat program yang disusun sebelumnya, cukup terlihat bahwa Dinas Pariwisata Maluku menitikberatkan pada unsur Atraksi (atractions) melalui event-event Nasional di dalam negeri maupun luar negeri yang dikategorikan dalam Media Lini Bawah (BTL). Dalam hal pengembangan ilmu dan teknologi, masih belum maksimal baik dari sisi biaya, implementasi media promosinya, serta konten-konten yang menginformasikan tentang kepariwisataan Maluku secara spesifik sesuai permintaan pasar Nusantara.

\section{Minutes (batasan Waktu);}

Untuk kepastian arah pengembangan promosi pemasaran, program strategi intergrasi brand 'Baronda Maluku' kedepan membutuhkan sebuah penyusunan perencanaan dalam bentuk 'Road Map Promosi', yaitu peta yang 
dipakai sebagai panduan untuk perjalanan kegiatan agar memiliki batasan waktu yang terukur. Adapun peta 'Road Map Promosi' 2018-2021 sebagai berikut ini:
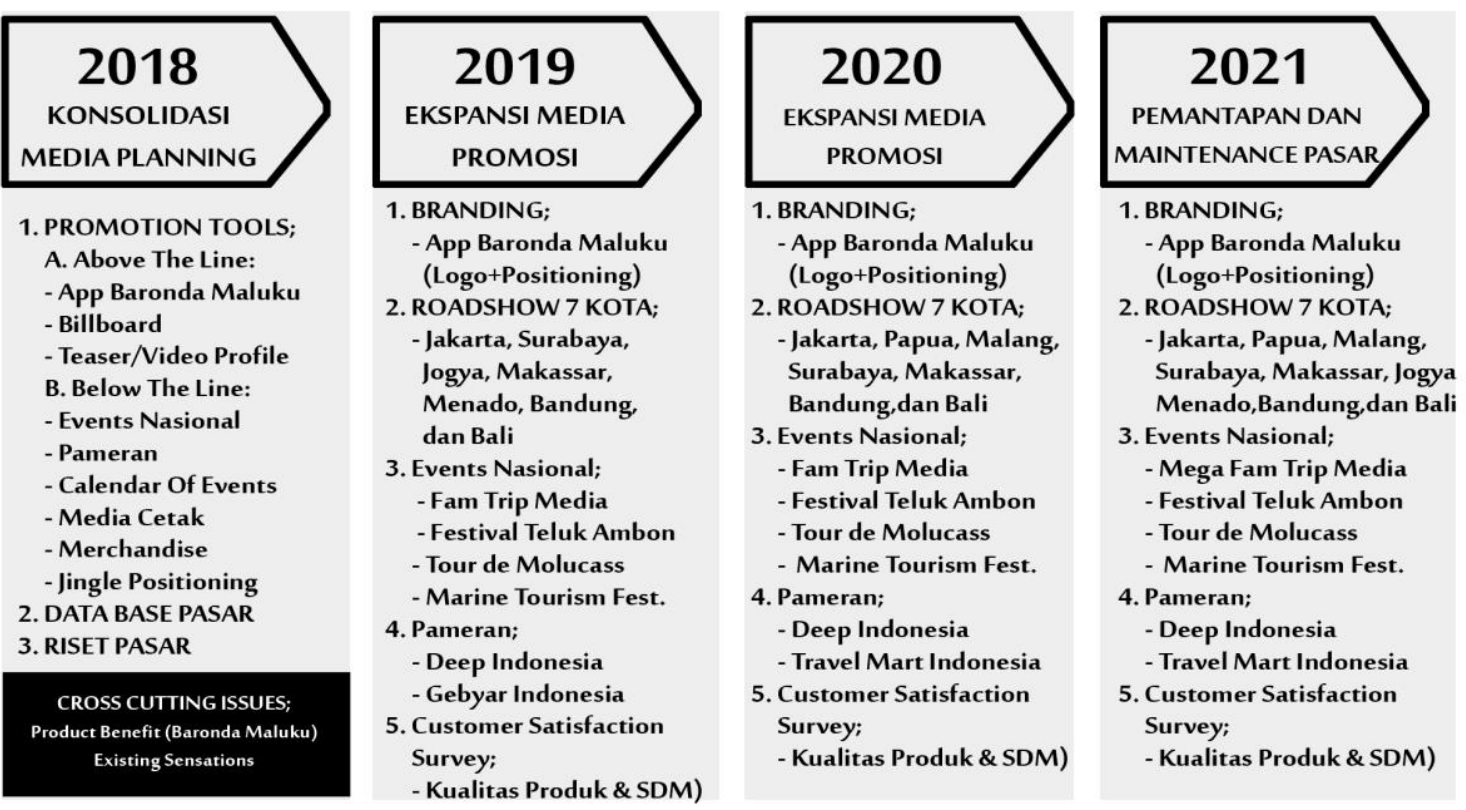

Gambar 3.6 Perencanaan Road Map Promosi 'Baronda Maluku' Tahun 2018-2021 Sumber: Perencanaan Road Map Promosi 2018-2021

\section{SIMPULAN}

Merujuk pada hasil penelitian peneliti menarik kesimpulan bahwa: (1) Hasil analisis pemetaan lingkungan industri pariwisata Maluku menjelaskan bahwa Dinas Pariwisata memiliki potensi pariwisata yang bervariasi diantaranya 440 wisata bahari, 222 daya tarik wisata budaya/sejarah serta 39 obyek wisata buatan yang tersebar di wilayah provinsi Maluku dengan memiliki keunikan disetiap masing masing obyeknya. Begitupun fasilitas penunjang seperti transportasi 47 angkutan kapal dan pesawat, akomodasi 235 penginapan (bintang dan non-bintang) dan 145 jenis usaha yang tersebar di sembilan kabupaten/kota; (2) Strategi Lintas Saluran di Dinas Pariwisata Maluku teridentifikasi masih sangat lemah. Strategi ini harus lebih diperkuat karena Informasi data yang mengalir/diterima berasal dari mereka yang menempati bagian-bagian fungsional yang memahami tentang teknis dilapangan. Penyerapan data melalui proses Down to
Up dapat memberikan kontribusi penting dalam penyusunan strategi media planning, media placement dan budgeting dalam penyusunan rencana kegiatan anggaran kedepannya; (3) Ancaman terhadap profitabilitas daerah cukup tinggi bila strategi komunikasi pemasaran yang dijalankan masih bertumpu pada media lini bawah (below the line) yang menitikberatkan pada atraksi/acara-acara tanpa adanya dukungan pemanfaatan media promosi digital online yang cakupan pasarnya luas. Sinergitas pemakaian media harus disertakan dengan menggabungkan lini atas (above the line) yang terintergrasi satu sama lain dengan lini bawah (below the line) yang media kreatifnya disusun berdasarkan pada permintaan data pasar; (4) Strategi Program Pemodelan Perjalanan Berwisata (travel pattern) di Maluku lebih diperkuat dan dipertajam, hal ini tentunya dirumuskan bersamasama antara stakeholder pemerintah di Sembilan Kabupaten/Kota bersama organisasi/pelaku usaha pariwisata lokal 
dan Nasional untuk mengakomodir kebutuhan calon wisatawan Nusantara ke depannya; (5) Adanya penyusunan strategi kreatif untuk dijadikan guidelines design sehingga Dinas Pariwisata memiliki sebuah pattern visual untuk mempromosikan sebuah identitas yang dapat dikomunikasikan secara simultan untuk memperkuat posisi tawar dalam penjualan produk wisata.; (6) Dinas Pariwisata Maluku disarankan untuk menerapkan Strategi komunikasi yang terintergrasi (intergrated marketing communication) melalui bauran promosi (promotion mix) yang dirancang dengan strategi kreatif untuk menghasilkan cara promosi melalui; interactive marketing, advertising, sales promotion, public relation dan personal selling dengan mengikuti kebutuhan permintaan pasar primer Nasional dengan penggunaan media komunikasi visual online; (7) Untuk kepastian arah pengembangan komunikasi pemasaran Dinas Pariwisata Maluku kedepan, diharapkan dapat menyusun program dasar strategi promosi berupa 'Road Map Promosi' sebagai acuan peta panduan perjalanan kegiatan yang memiliki fase-fase terukur baik jangka pendek, menengah dan jangka panjang.

\section{DAFTAR PUSTAKA}

Avraham, E., \& Ketter, E. (2008). Media Strategies for Marketing Places In Crisis. UK: Elsevier Inc.

Belch, M.A., \& Belch, G.E. (2001). Advertising and Promotion: An Integrated Marketing Communications Perspective. 5th Ed. New York: McGraw-Hill.

Creswell, J.W. (2009). Research Design. Qualitative, Quantitative, and Mixed Methods. Third Edition. Thousand Oaks California.

Dokumen Laporan Dinas Pariwisata Provinsi Maluku. (2017). Rencana Strategis (RENSTRA) Pariwisata Maluku 2017.

Gelder, S.v. (2005). Global Brand Strategy: Unlocking Branding
Potential Across. Countries, Cultures \& Markets. Jakarta: PT Gramedia Pustaka Utama.

https://www.youtube.com/watch?v=aC0 XfyhoK90, Talkshow Rakornas: Bersama Ibu Habiba kepala dinas pariwisata provinsi Maluku

https://ambon.antaranews.com/berita/ 43231/dispar-maluku-gelardiseminasi-pemasaran-melaluiitx, Dispar Maluku gelar diseminasi pemasaran melalui ITX

https://swa.co.id/swa/businessstrategy/pemda-raja-ampattargetkan-2-ribu-turis

http://sulselprov.go.id/post/disbudparlaunching-brandingpariwisatasulsel

Ilyas, M. (2009). Strategi Pengembangan Pariwisata Kepulauan Togean di Kabupaten Tojo Una-una. Tesis. Program Studi Perencanaan Pengembangan Wilayah. Program Pascasarjana Universitas Hasanudin

Kasali, R. (1998). Membidik Pasar Indonesia. Jakarta: PT. Gramedia Pustaka Utama.

Kotler, P., Bowen, J.T., \& Maken, J.C. (2005). Marketing for Hospitality and Tourism. Fourth Edition. Pearson International Edition.

Kotler, P. (1992). Manajemen Pemasaran: Analisis, Perencanaan, Implementasi dan Pengendalian. Edisi Keenam. (Diterjemahkan oleh Drs. Jaka Wasana,

MSM). Jakarta: Penerbit Erlangga.

Morissan. (2010). Periklanan Dalam Komunikasi Pemasaran Terpadu. Edisi pertama. Jakarta: Penerbit Kencana.

Pike, S. (2008). Destination Marketing: An Integrated Marketing Communication Approach. First edition. UK: Elsevier Inc.

Pitana, G., \& Diarta, I.K.S. (2009). Pengantar Ilmu Pariwisata. Yogyakarta:CV Andi Offset.

Smith, P.R. (1998). Marketing Communications: An Integrated 
Approach. 2nd Ed. London: Kogan Page.

Smith, D.R. (2005). Strategic Planning For Public Relations. 2nd Edition. London: Lawrence Erlbaum Associates Publisher.

Smith, P.R. (1999). Strategy Marketing Communication. SOSTAC Analysis.
Revised edition. Great Britain: Clays Ltd, St Ives plc.

UU No. 1 tentang Penerbangan dan PM. 69 (2013). Tatanan Kebandara udaraan Nasional-Kementerian Perhubungan Republik Indonesia. Yoeti. (1992). Pengantar Ilmu Pariwisata. Jakarta: Pradnya Paramita. 